\title{
BARRAGEM NORTE E SUAS INFLUÊNCIAS SOCIOESPACIAIS NO MUNICÍPIO DE JOSÉ BOITEUX - SC: UM OLHAR SOBRE AS COMUNIDADES ATINGIDAS
}

\author{
Marcia Fusinato Barbosa Athayde ${ }^{1}$ \\ Pedro Martins ${ }^{2}$
}

Resumo: Este artigo resulta de uma pesquisa cujo objetivo foi identificar influências da implantação da Barragem Norte na formação socioespacial em José Boiteux - SC. A obra integra o complexo de barragens de contenção de enchentes no Vale do Itajaí e atinge terras indígenas e de uso agrícola no alto curso do Rio Itajaí do Norte. O estudo ampara-se na perspectiva geográfica de formação socioespacial dada por Milton Santos e concepções de Sílvio Coelho dos Santos, Sálvio Alexandre Müller, Pedro Martins e Nilson Fraga. O universo de pesquisa foi o município de José Boiteux. O recorte temporal entre 1972 e 2016. Os dados foram obtidos mediante fontes documentais, observação participante e entrevistas com pessoas das comunidades atingidas, revelando que os efeitos da obra influenciaram e influenciam as comunidades locais e o município como um todo.

Palavras-chave: Barragem Norte; Vale do Itajaí; Comunidades atingidas; Saberes locais

\section{NORTH DAM AND ITS SOCIO-SPATIAL INFLUENCES IN THE MUNICIPALITY OF JOSÉ BOITEUX - SC: A LOOK AT THE AFFECTED COMMUNITIES}

\begin{abstract}
This article results from a research whose objective was to identify influences of the implementation of de Nort Dam in the socio-spatial formation in José Boiteux -SC. The project integrates the complex flood containment dams in the Itajaí Walley and reaches indígenous and agricultural lands in the upper Nort Itajaí River. The study is based on the geographical perspective os socio-spatial formation given by Milton Santos anf conceptions of Sílvio Coelho dos Santos, Sálvio Alexandre Müller, Pedro Martins and Nilson Fraga. The research universe was the county. The time was between 1972 and 2016. Data ware obtained through documentary sources, observation and interviews with people from affected communities and the municipality as a whole.
\end{abstract}

Keywords: Barragem Norte; Vale do Itajai; Affected communities; Local knowledge

\section{REPRESA NORTE Y SUS INFLUENCIAS SOCIO ESPACIALES EN EL AYUNTAMIENTO DE JOSÉ BOITEUX - SC: UNA MIRADA SOBRE LAS COMUNIDADES AFECTADAS}

Resume: Este artículo resulta de una investigación cuyo objetivo fue identificar influencias de la implantación de la Represa Norte en la formación socioespacial en José Boiteux - SC.

\footnotetext{
${ }^{1}$ Mestre em Planejamento Territorial e Desenvolvimento Socioambiental pelo PPGPLAN/UDESC; professora de Geografia da Rede Estadual de Educação na Escola de Educação Básica Gertrud Aichinger, em Ibirama/SC.

${ }^{2}$ Doutor em Antropologia pela Universidade de São Paulo; professor do PPGPLAN/UDESC.
} 
La obra integra el complejo de represas de contención de inundaciones en el Valle de Itajaí y alcanza tierras indígenas y de uso agrícola en el alto lecho del río Itajaí do Norte. El estudio se fundamenta en la perspectiva geográfica de Milton Santos sobre el concepto de formación socioespacial y en el trabajo conceptual de otros autores como Sílvio Coelho dos Santos, Sálvio Alexandre Müller, Pedro Martins y Nilson Fraga. El universo de pesquisa fue el município de José Boiteux. El recorte temporal comprende el período desde 1972 hasta 2016. Los datos fueron obtenidos mediante fuentes documentales, observación participante y entrevistas con personas de las comunidades afectadas, revelando que los efectos de la obra influyeron e influyen sobre las comunidades locales y el municipio como un todo.

Palabras clave: Represa Norte; Valle de Itajaí; Comunidades afectadas; Saberes locales

\section{INTRODUÇÃO}

A Barragem Norte, grande obra de engenharia cujos efeitos sobre a população local constituem o objeto central deste estudo, está localizada na Barra do Rio Dollmann, município de José Boiteux - SC - sendo este um pequeno município do Vale do Itajaí do Norte que integra a mesorregião do Vale do Itajaí. Segundo dados do IBGE (2010) o município abrigava naquele ano uma população de 4.721 habitantes formada, em grande parte, por povos indígenas dos grupos Xokleng, Kaingang e Guarani, descendentes de colonos, principalmente de cultura italiana, alemã e açoriana e um grupo étnico que se identifica e é identificado como Comunidade Cafuza. Em 2016, segundo estimativas, a população de José Boiteux ainda não atingiu a marca de 5 mil habitantes.

O principal rio que corta o território é o Itajaí do Norte ou Hercílio, receptor de águas de vários afluentes. A área de abrangência e arredores do lago da Barragem Norte era originalmente coberta pela Mata Atlântica - substituída parcialmente por plantações, pastagens e reflorestamentos à base de espécies exóticas.

O maciço da barragem foi erguido, a partir de 1972, logo a jusante da confluência do Rio Dollmann com o Rio Itajaí do Norte e próximo dos limites da Terra Indígena Xokleng/Laklãnõ. A obra foi projetada e executada com o fim específico de conter enchentes que afetam cidades do Baixo e Médio Vale do Itajaí. Seu lago de contenção atinge as terras de várzea que antes da obra eram habitadas pelos povos Xokleng e Kaingang, pelo grupo Cafuzo inserido na área no final da década de 1940 e pelo grupo Mbya-Guarani lá instalado no início dos anos de 1950. Também atinge terras agricultáveis situadas às margens do Rio Dollmann, as quais eram utilizadas por descendentes de colonos instalados no lugar desde meados da segunda década do século XX. 
Com a implantação da Barragem Norte, todas essas comunidades foram forçadas a se deslocar. Boa parte dos indígenas migraram para fora da área e os que permaneceram tiveram suas moradias deslocadas para as encostas ao longo do rio. O grupo Cafuzo foi relocalizado em outra área do município e os moradores de Barra do Rio Dollmann dispersaram-se, alguns localizaram-se nos limites da área de segurança da barragem mas a maior parte migrou para outras cidades.

Foi esse contexto que motivou o presente estudo e a questão problema norteadora ficou definida pela indagação: quais são as influências da Barragem Norte na formação socioespacial do Município de José Boiteux? O objetivo estabelecido para responder à questão foi identificar as influências da implantação dessa obra na formação socioespacial do lugar no contexto regional.

$\mathrm{O}$ estudo tem como foco as comunidades atingidas pela obra e se orienta pelo olhar acerca de uma realidade que permite pensar sobre outras com características similares. Constitui-se como investigação atenta ao contexto da construção de barragens, geralmente implantadas sem que as comunidades por elas atingidas tenham noção dos seus efeitos globais.

A escolha do tema justifica-se em função da relevância social e das contribuições que pode oferecer no sentido de subsidiar o planejamento e gestão do desenvolvimento local. Em âmbito científico, pela produção de conhecimentos úteis à compreensão das particularidades do modo de evolução e organização social, política e econômica de comunidades marcadas por intervenções que as influenciam positiva ou negativamente.

O olhar lançado sobre o caso específico da Barragem Norte, através deste trabalho, permite pensar sobre outras situações similares existentes no mundo e leva a refletir sobre a viabilidade do uso de medidas estruturais como estratégia de minimização dos problemas causados por enchentes.

\section{Procedimentos metodológicos}

O estudo se inclui no campo das pesquisas sociais. É desenvolvido através da pesquisa qualitativa que, segundo Minayo (2001), favorece as investigações com foco na identificação e compreensão do significado das ações e relações dos grupos humanos entre si e com seu ambiente de vida. Os dados utilizados no desenvolvimento desta investigação, e respectivas discussões e considerações que se fazem ao final do trabalho, resultam da construção de um 
referencial teórico, da revisão da literatura sobre o tema (estado da arte) e da coleta de dados empíricos através de entrevistas e depoimentos obtidos na pesquisa de campo e na observação sistemática do cotidiano do entorno da barragem - sendo esta última técnica definida como observação participante. Todos estes elementos permitiram formular percepções a respeito da realidade vivida pelas comunidades em questão sem desconsiderar que elas se encontram inseridas em um universo maior. As entrevistas, coleta de depoimentos e observação participante trataram de levantar dados que pusessem em evidência os sentimentos e as reações de cada uma dessas comunidades frente às influências da Barragem Norte sobre seus espaços de vida nos diferentes momentos desse processo.

\section{Vale do Itajaí, a questão das enchentes e a Barragem Norte}

A discussão relacionada ao Vale do Itajaí como recorte espacial em que se insere o município de José Boiteux (município sede da Barragem Norte) é feita a partir do entendimento de Santos no sentido de que "nenhum enfoque que deixe de lado a noção de totalidade permitirá uma correta noção da realidade" (2008, p.27).

O município localiza-se no Alto Vale do Itajaí, na Bacia Hidrográfica do Itajaí que compõe a Vertente Atlântica em Santa Catarina. As características geológicas e geomorfológicas desta bacia hidrográfica permitiram, para fins de identificação e estudos, sua divisão em três áreas: Baixo Vale, Médio Vale e Alto Vale. O Baixo Vale é uma área de relevo pouco acentuado, ocupação humana relativamente alta e urbanização significativa em relação às outras áreas do Vale. Compreende, entre outras, a cidade de Blumenau, historicamente atingida por enchentes. O Médio Vale é uma área com relevo mais acentuado em relação ao Baixo Vale. Tem ocupação humana menos intensa e uso dos solos alternado por atividades rurais e urbanas. O Alto Vale, por sua vez, é uma área com relevo predominantemente declivoso, com solos utilizados basicamente para atividades agrárias e com menores índices de ocupação humana em comparação às demais áreas da bacia hidrográfica.

Para tornar mais clara a situação em estudo explica-se que, desde o início do processo de ocupação dessa região catarinense, as populações que se fixaram nas cidades instaladas ao longo do Vale do Itajaí, principalmente nas áreas de planícies de inundação, tiveram que conviver com enchentes periódicas. 
Sobre o histórico de enchentes que atinge essa área, Frank (2003) realizou registro das datas de cheias em Blumenau e elencou ações planejadas e realizadas para a minimização do problema. Segundo a autora, entre 1852 e 2011 ocorreram 72 enchentes no Vale do Itajaí atingindo, mais intensamente, Blumenau. Posteriormente, outras ocorreram colocando em alerta as populações das cidades do Médio e Baixo Vale. Das medidas mitigadoras para o problema, ela afirma que desde 1911 (ano da segunda grande enchente após a criação da Colônia Blumenau) as medidas de mitigação passaram a ser sugeridas. A ocupação da cidade de Blumenau e de outras cidades do Vale do Itajaí intensificou-se agravando o problema e mobilizando as comunidades atingidas. Os atingidos pelas enchentes passaram a cobrar das autoridades medidas para amenizar o problema.

Ainda segundo Frank (2003), na segunda metade da década de 1950, em decorrência da reincidência de enchentes, instituições da sociedade civil e setores do poder público organizaram-se para encontrar saídas para a questão. Assim, na década de 1960 foi colocada em prática a proposta da construção de barragens em diferentes pontos da Bacia do Itajaí. A escolha dos lugares para instalação das obras, no entanto, levou em conta os aspectos políticos e não o posicionamento das comunidades em que os empreendimentos seriam realizados.

As barragens citadas foram destinadas ao Alto Vale, pois compreendia-se que a dinâmica das enchentes se relacionava com os índices pluviométricos regionais. Foram executados três empreendimentos: em Ituporanga (Barragem Sul), Taió (Barragem Oeste) e José Boiteux (Barragem Norte). É em relação a esta última barragem que versa este trabalho.

De acordo com Fraga (1997), a construção da Barragem Norte foi iniciada em 1976 e finalizada em 1992. Durante boa parte desse processo José Boiteux, que só foi emancipado em 1989, era distrito do município de Ibirama, por isso a literatura facilmente trata a Barragem Norte como Barragem de Ibirama e a Terra Indígena Xokleng/Laklãnõ como Terra Indígena de Ibirama ${ }^{3}$.

Destaca-se que muitos estudos já foram efetuados para investigar as consequências da Barragem Norte para as comunidades atingidas, como os trabalhos de Santos (1987), Müller (1987), Martins (1995), Fraga (1997) e Crépeau (2008), este último destacando, especialmente, a produção de Sílvio Coelho dos Santos sobre os grupos Jê, o que implica em enfatizar o impacto das barragens sobre os povos indígenas. Assim, o que se faz aqui é lançar um olhar sobre a literatura já produzida e em consonância com a voz contemporânea das comunidades locais para se obter uma visão atualizada da totalidade das influências desta obra

\footnotetext{
${ }^{3}$ Nos primórdios da estruturação dessa terra indígena pelos órgãos federais o lugar foi nominado como Posto Indígena Duque de Caxias sendo, posteriormente, sucessivamente renominado.
} 
que foi construída com o intuito de mitigar efeitos das enchentes para as populações localizadas à sua jusante, em detrimento daquelas que se encontram à montante e no seu entorno mais próximo.

Comparada às outras obras do complexo de barragens de contenção de cheias do Vale do Itajaí, considerando os transtornos e medos que causou e ainda causa à sociedade regional no transcurso de sua construção e pelo próprio espaço geográfico onde se encontra situada, a Barragem Norte oferece razões para que se possa, a partir dela, refletir sobre a validade deste tipo de intervenção como medida de mitigação de enchentes.

Reitera-se que, em comparação com outros grandes empreendimentos, como é o caso de muitas hidrelétricas construídas no Brasil e em outros lugares do mundo, esse empreendimento pode não ter atingido tão grande número de habitantes mas, indiscutivelmente, causou efeitos perversos sobre as comunidades atingidas. Basta se ter em mente o que constatou Santos (1997) quando se referia ao projeto com a afirmação de que essa foi uma obra executada sem levar em conta a legislação ambiental, tampouco a necessidade de elaboração de relatório de impacto ambiental, muito menos se fez sob uma licença de operação. Nas palavras do autor, "pode-se dizer que esta obra acabou se tornando um exemplo de como não se deve construir uma barragem" (p. 115). Sua implantação, no município de José Boiteux, é uma questão que ainda produz graves reflexões sobre as transformações por ela ocasionadas não somente em nível local como também no plano regional.

\section{A Barragem Norte e suas influências socioespaciais}

A discussão sobre a questão da Barragem Norte e suas influências socioespaciais é feita com base na percepção de que o espaço deve ser considerado como conjunto indissociável onde participam, de um lado, certo arranjo de objetos geográficos, naturais e sociais e, de outro, a vida que os preenche e os anima. Visto deste modo, afirma Santos que "o espaço tem um papel privilegiado, uma vez que ele cristaliza os momentos anteriores e é o lugar de encontro entre esse passado e o futuro, mediante as relações sociais do presente que nele se realizam" (1979, p. 122). Para este autor, "O conteúdo (da sociedade) não é independente da forma (objetos geográficos) e cada forma encerra uma fração do conteúdo. $\mathrm{O}$ espaço é, então, um conjunto de formas, contendo cada qual frações da sociedade em 
movimento" (2008, p. 10). Assim visto, o espaço é considerado como totalidade no conjunto que envolve as relações de uma sociedade com o meio, tanto no passado quanto no presente.

Assim, a abordagem relativa à identificação das influências da Barragem Norte na formação socioespacial em José Boiteux leva em conta os seus efeitos para as comunidades atingidas sem desconsiderar as demais esferas geográficas em que se inserem. Uma investigação que se faz a partir da compreensão que a reflexão sobre esta realidade permite pensar também sobre outras similares. Para efetuá-la, apresenta-se, antes de tudo, o conceito de atingidos que, na situação enfocada, define os atingidos por barragens no contexto dos projetos de construção de barragens hidrelétricas. Sobre este conceito, afirma Vainer que "Sendo essencialmente uma categoria social em disputa, a noção de atingido varia no tempo e no espaço, conforme os contextos políticos e culturais” (2007, p. 40). Para o autor, o conceito de atingido diz respeito ao reconhecimento de direitos, sendo necessário compreender que quando se afirma que um grupo, família ou indivíduo é ou foi atingido por um certo empreendimento, significa reconhecer como legítimo e, em alguns casos, como legal o direito de ressarcimento ou indenização, reabilitação ou reparação não pecuniária por perdas materiais ou imateriais decorrentes desse empreendimento.

Deste modo, representadas por seus integrantes, as comunidades atingidas pela Barragem Norte incluem agricultores que detinham título de propriedade da terras, indígenas que tinham como base da sua sobrevivência as terras da Área Indígena destinadas à coletividade e os Cafuzos, que também habitavam o mesmo território.

Reitera-se que, como parte integrante do conjunto de medidas estruturais destinadas ao controle de enchentes no Vale do Itajaí, a Barragem Norte constituiu-se como estratégia de proteção das comunidades atingidas por enchentes. Isso criou uma situação inversa. Se antes as populações das cidades do Médio e Baixo Vale sofriam o risco de enchentes, a realização da obra colocou em risco e em situação de vulnerabilidade, mesmo que em outras condições, a comunidade que sediou o empreendimento e aquelas que se encontram à montante do local de Barramento das águas.

Importa dizer que a barragem edificada na Barra do Rio Dollmann, José Boiteux, em alguns momentos já deu mostras de que se presta à finalidade para a qual foi construída. Ainda restam, no entanto, dúvidas sobre sua eficiência como medida de proteção contra enchentes para as comunidades do Baixo e Médio Vale do Itajaí. A suposta proteção que ela oferece permanece como incógnita. Apesar disto, uma coisa é certa: as comunidades que foram atingidas pela sua implantação sofreram transformações determinantes em todas as dimensões da vida. 
Santos (1987b), ao referir-se aos impactos da obra sobre os povos indígenas que viviam no espaço inundável do futuro lago durante os períodos chuvosos, afirma que os prejuízos materiais e imateriais para os povos locais são muitos. Em sua percepção, a desestruturação social tornou-se evidente. A miscigenação entre brancos e índios e entre índios e "mestiços" transformou-se em rotina por conta da proximidade e do encantamento do modo de vida na cultura ocidental. $\mathrm{O}$ individualismo, já presente, de certa forma, na tradição Xokleng, passou a ser exercido de modo exacerbado e alheio ao controle social tradicional.

Na mesma linha, Müller (1987) destaca as ações de depredação dos recursos naturais existentes na área e afirma:

A exploração dos recursos florestais disponíveis na Área Indígena foi consequência imediata. Primeiro, os indígenas foram estimulados a comercializar o palmito, atendendo às ofertas de empresas dedicadas à fabricação de conservas. Depois, as madeiras nobres tornaram-se objeto de negociações, na maioria das vezes nada honestas (p. 60).

Ainda sobre as consequências da obra, Müller (1987) e Santos (1997) destacam as mudanças advindas do deslocamento das habitações indígenas das áreas de várzea para as encostas, tornando-se impossível manter certos hábitos culturais até então preservados.

Em relação à questão da madeira, também Martins (1995) explica que a extração madeireira, já realizada em tempos anteriores ao grande projeto de construção da barragem, intensificou-se com a deflagração da obra:

A extração dessa madeira já vinha ocorrendo[...], mas acontecia em ritmo lento, em virtude da ausência de estradas de acesso à floresta, não chegando a comprometer o equilíbrio ecológico da Área. As árvores retiradas eram cortadas a machado e transportadas para fora da àrea com o auxílio de tração animal - o que impedia a devastação. A partir de 1974, com o início da construção da Barragem Norte, essa situação começou a mudar (p. 98).

Esta afirmação deixa evidente que a relação de exploração de recursos florestais realizada no lugar até aquele momento não causava grandes impactos ao ecossistema pois era realizada sem grandes agressões ao meio ambiente.

A respeito das consequências desse processo para o Povo Cafuzo, Martins (1995) explica que os efeitos da obra e as mudanças estruturais e culturais enfrentadas pelos Cafuzos frente à implantação da barragem envolve o drama decorrente da desapropriação do espaço que seria tomado pelo lago de inundação e pela abertura da estrada de contorno da obra. Nas 
suas palavras, "Com a desapropriação de terras exigida pela implantação do lago da barragem, a área até então disponível para os Cafuzos - cerca de mil hectares - ficou reduzida a menos de dois terços" (p. 99). Na percepção do autor, "a redução do território fez com que Xokleng e Cafuzos passassem a disputar o mesmo espaço e os Xokleng, como proprietários da área, tinham a primazia da escolha” (p 101). Essa situação dificultou a sobrevivência dos Cafuzos no interior da Terra Indígena, fez aflorar conflitos latentes entre eles e os indígenas forçando, finalmente, a saída do Grupo Cafuzo da área.

Ao tratar do tema, também Fraga (1997) entende que a execução da obra incidiu diretamente no modo de vida das comunidades residentes nas terras indígenas e sobre a comunidade de Barra do Rio Dollmann. Menciona as mudanças nas relações entre brancos e índios e entre índios e Cafuzos a partir do momento em que se deu a supressão das terras cultiváveis ocupadas pelos indígenas. Sobre a totalidade dos efeitos da obra, reitera que a obra causou desgaste econômico e ambiental mas também político, o que acabou por inserir as populações indígenas locais em um contexto de muitas tensões que atravessaram as décadas de 1980 até o início do século XXI e, podemos acrescentar, até o presente. Do ponto de vista de Fraga na obra citada, a pobreza em que os indígenas foram inseridos e sua dependência em relação à sociedade regional causou sobre aquela população efeitos perversos.

Acerca das influências da obra na vida dos agricultores que habitavam a Barra do Rio Dollmann, afirma Fraga (1997) que muitos tiveram a total ou parcial indenização das terras mas, ao migrar para áreas urbanas, sofreram os impactos da adaptação ao novo meio. Em outra abordagem, Fraga (2000) discorre sobre o jogo de forças que se estabelece no meio empresarial e político local e regional em virtude de recursos destinados às obras de contenção e prevenção de enchentes no Vale do Itajaí. Menciona que a problemática das enchentes provoca o que ele define como ciclo vicioso que perdura em torno da busca de recursos e do discurso da resolução dos problemas que afetam as populações atingidas e populações protegidas pela barragem.

Munida de um olhar que parte do interior da comunidade indígena, Patté (2015) busca, na voz do seu povo, identificar e analisar as consequências socioambientais da obra para a sua comunidade. A autora afirma que, entre outras mudanças, a Barragem Norte causou a divisão política da comunidade indígena:

Atualmente a Terra dos Laklãnõ (Xokleng) se encontra dividida politicamente em oito (08) aldeias por linhas imaginárias determinada pelos caciques regionais que são responsáveis pelo desmembramento de aldeias, conforme prevê o Regimento Interno Laklãnõ que é a lei 
interna que regula a política e a organização da liderança interna do povo. Todas as aldeias são independentes entre si, mantendo unidade através do Cacique Presidente (Geral) que representa toda a Terra Indígena perante as instituições e órgãos com os quais mantem relações políticas (p.14).

A citação destacada evidencia as influências da barragem no modo de organização social e política do grupo. Isso acabou por favorecer o desenvolvimento de uma política interna de organização social diferenciada em relação ao período anterior à construção da barragem. Sobre os impactos ambientais, a mesma autora afirma que "as enchentes acabaram com todo solo fértil e a mata ciliar, além de muitas espécies de peixes e outros animais que habitavam as regiões alagadas” (p. 11). Isto forçou as comunidades a mudar suas práticas e estratégias de sobrevivência.

O que se depreende dos argumentos aqui reunidos, é que a implantação daquela barragem, voltada para a proteção de populações residentes à sua jusante, alterou profundamente o modo de vida, a organização social, econômica e política das comunidades locais, exigindo a sua readaptação no local ou adaptação a novos espaços e atividades até então desconhecidos.

\section{Barragem Norte: o olhar e as percepções das comunidades atingidas}

A análise que se pode fazer acerca das influências da Barragem Norte, a partir do olhar e percepções dos próprios atingidos, precisa considerar os diferentes aspectos que envolvem a sua sobrevivência e todas as novas etapas e/ou eventos enfrentados por eles em razão da implantação da obra. É preciso também levar em conta a indissociabilidade existente entre todos os aspectos da vida em comunidade. Considera-se, neste sentido, os aspectos ambientais, sociais, econômicos e políticos que sempre estão relacionados a uma determinada cultura.

Para a comunidade de Barra do Rio Dollmann, formada por indivíduos habituados à vida no campo, as mudanças foram muito radicais. A implantação da barragem, destinada à proteção de outras populações contra enchentes, tomou-lhes o espaço produtivo e as próprias moradias. Sem o direito de escolha, viram-se obrigados a aceitar uma indenização nada compatível com as perdas sofridas. Na declaração de um antigo morador da localidade, " $A$ 
barragem foi uma decisão do governo. Ninguém discutia. A indenização para alguns foi boa, mas para outros não cobriu nem a despesa com a compra de outro terreno" ${ }^{\text {. }}$.

Uma descendente de um antigo morador do lugar, que teve indenização parcial da propriedade agrícola e que insistiu em permanecer na pequena porção de terras que lhe restou, pronunciou-se sobre as implicações da obra para a comunidade:

Quando tivemos notícia a barragem já era coisa certa. O governo não ia voltar atrás. Eram famílias que tinham sua história ali. Não tem dinheiro que pague o que se perdeu. O pessoal foi indenizado e de começo isso iludiu muita gente. Quem morou lá perdeu não só a terra. Perdeu tudo o que tinha de referência. A comunidade não está mais lá. Você e qualquer pessoa que se mudar para outra cidade, quando volta para o lugar de onde saiu encontra os amigos. Mas nós, vamos ver o que? Muitas famílias migraram logo de inicio. Outras ficaram um tempo, mas tiveram que mudar para outras cidades. A Barra Dollmann, aos poucos, virou uma área de conflito ${ }^{5}$.

O depoimento acima destacado leva a compreender que mensurar as consequências da obra para aquela comunidade talvez seja impossível. Em curto espaço de tempo, famílias foram forçadas a migrar do campo para a cidade. Da vida tranquila no campo e do uso de saberes locais para a produção de bens necessários à sobrevivência, tiveram que se ajustar ao ritmo de vida operária. Poucos tiveram como adquirir novas propriedades agrícolas em substituição às que foram obrigados a deixar por força da desapropriação e em favor da implantação da barragem.

As comunidades indígenas da Terra Xokleng/Lãklanõ, habituadas à vida coletiva em relações harmoniosas com a natureza, foram levadas a adotar novos hábitos. O contato com comunidades não indígenas, acostumadas ao modo de vida predominante na cultura ocidental e na sociedade nacional, já era vivenciado antes da barragem. Mas, ainda que se pudesse levar em conta que essas comunidades já haviam incorporado costumes não nativos antes da implantação da obra, foi a partir da sua construção que se desencadearam mudanças de grande impacto nas suas relações socioambientais.

Para evidenciar as transformações que se processaram no lugar, destaca-se o depoimento de um homem Kaingang: “a barragem provocou estrago muito grande na vida do povo indígena. Antes, o índio vivia organizado na aldeia, vivia da sua plantação e do que tirava da terra. A barragem desorganizou, empurrou o índio para outro tempo, outro tipo de

\footnotetext{
${ }^{4}$ Entrevista realizada em 21 de dezembro de 2015.

${ }^{5}$ Depoimento colhido em 21 de novembro de 2015.
} 


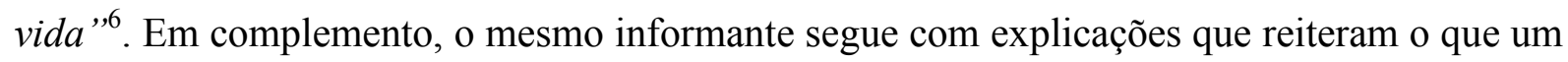
rápido olhar sobre a paisagem local revela: “Com a construção da barragem, o povo índio foi obrigado a deixar o leito e as margens do rio onde a terra era fértil, onde tinha todo o sustento, desde o peixe até a plantação e a fruta. Tudo passou a ficar debaixo d'agua cada vez que vinha a chuva".

Müller (1987) e Santos (1997) também já haviam constatado que a primeira grande mudança no modo de vida dessas comunidades era representada pelo súbito deslocamento das famílias das áreas de várzea, às margens do rio Hercílio ou Itajaí do Norte, onde viviam integradas ao ambiente. A relocalização e a motivação ou necessidade de recorrer às trocas comerciais para suprir a falta de produtos até então encontrados facilmente em seu entorno foram impulsionadores de muitas outras mudanças.

São várias as situações que tornam perceptíveis as mudanças no modo de organização social, política e econômica desses povos, como registra Patté (2015). A luta pela ampliação e redemarcação dos limites territoriais; as mudanças no modo de vida das pessoas acostumadas à jornada do sol e que passaram a ter uma jornada de trabalho comandada por patrões que os empregam, muitas vezes, em troca de baixos salários; a divisão da única aldeia em várias; a forma de escolha das lideranças locais, que segue padrões nada compatíveis com o modo tradicional de organização social; as constantes manifestações e conflitos entre indígenas e colonos, que lutam pelo direito à terra, publicados nos meios de comunicação locais e regionais; a luta dos indígenas da Terra Laklãnõ em favor do ressarcimento das perdas que sofreram; a ocupação da área correspondente ao antigo canteiro de obras da Barragem Norte, realizada com o intuito maior de instalar uma nova aldeia, portanto um novo território, são, entre outros acontecimentos, consequências diretas da implantação da barragem para os povos indígenas locais.

É um fato incontestável que a Comunidade Cafuza também sofreu influências advindas da implantação da obra. Sobre este grupo social, Santos (1994), em entrevista, declara que ele foi vítima direta da barragem. Para o antropólogo, mesmo que os Cafuzos tenham chegado à conquista da terra para reassentamento em local próprio, nada os impede de terem uma discussão jurídica sobre os direitos que eles realmente tinham enquanto comunidade atingida. A implantação da Barragem Norte foi fator crucial na mobilização desta Comunidade e das instituições envolvidas em favor da sua relocalização. Após tornadas insustentáveis as condições de sobrevivência do grupo no interior da Terra Indígena, a saída

\footnotetext{
${ }^{6}$ Depoimento colhido em 23 de fevereiro de 2016.
} 
encontrada foi lutar com o intuito de garantir a sobrevivência, o resgate da identidade e construção de um novo território.

É possível afirmar que, dentre as comunidades atingidas pela obra, a Comunidade Cafuza passou por momentos críticos a ponto de viver o risco de desintegração. No entanto, com a união dos seus membros e com apoio institucional para o enfrentamento das adversidades, o grupo encontrou forças para lutar em favor de uma terra de uso coletivo onde pudesse reconstruir sua vida. Ao indagar membros da comunidade a respeito da implantação da barragem e das influências dessa obra na vida do Povo Cafuzo dentro da Terra Indígena, as respostas obtidas colocaram em evidência o sentimento de que foi a partir desse momento que a Comunidade Cafuza passou a sentir que os Cafuzos não eram donos da terra.

As batalhas enfrentadas por essa comunidade, em decorrência da construção da Barragem Norte, foram muito significativas. Assim se expressa um membro da comunidade: "Na Reserva indígena o povo viveu enquanto dava. Lá a vida foi difícil. De uma hora para outra a terra de plantar não era mais do povo. Antes da barragem a gente até vivia tranquilo. Mas, foi acontecer a primeira enchente e não teve mais como viver lá ${ }^{7}$.

O depoimento destacado confirma a situação vivida pelo Povo Cafuzo no Interior da Terra Indígena após deflagrada a Construção da barragem, conforme registrado por Martins (1995). Atualmente os Cafuzos encontram-se assentados na localidade de Alto Rio Laeiscz, dentro dos limites do município de José Boiteux. A conquista do espaço para a construção do novo território e para reorganizar a vida se deu com amparo institucional universitário e do Instituto Nacional de Colonização e Reforma Agrária. No entanto, mesmo já tendo realizado o sonho da conquista da terra de uso comum, a comunidade ainda enfrenta percalços.

Entretanto, é possível afirmar que, em função de saberes locais específicos e em virtude da valorização do modo de vida em coletividade, os Cafuzos encontraram no cultivo da erva-mate e em outras atividades alternativas de sobrevivência a possibilidade de efetivação de um modo de vida baseado no desenvolvimento territorial sustentável.

Observa-se, de qualquer forma, que as comunidades aqui citadas como atingidas pela construção da Barragem Norte buscam constantemente novas formas de lidar com as influências dessa obra em suas vidas. Buscam nos saberes locais e na constante reinvenção dos seus costumes a possibilidade de pensar e atuar no enfrentamento dos desafios que surgem a cada novo momento.

\footnotetext{
${ }^{7}$ Depoimento obtido no dia 07 de fevereiro de 2016.
} 


\section{Considerações Finais}

A proposta inicial desta pesquisa foi identificar as influências da Barragem Norte na formação socioespacial em José Boiteux. Verificou-se que, a exemplo de outras situações, as influências dessa obra ocasionaram mudanças nas diferentes dimensões da vida de cada uma das comunidades atingidas. Isso repercutiu não somente em nível local mas também nas demais dimensões espaciais com que essas comunidades se relacionam.

A Comunidade Indígena passou por mudanças drásticas no modo de organização social, política e econômica. Atualmente está dividida em oito aldeias. O grupo Guarani sofre o isolamento dentro da própria Terra Indígena. Os Kaingang e Xokleng, através de manifestações constantes, lutam incansavelmente em busca da autoafirmação e na tentativa de resgatar a própria história e a sua identidade. Buscam, mediante a valorização dos saberes locais, a possibilidade de promover o desenvolvimento socioambiental. Querem a redemarcação dos limites territoriais e, neste processo, batalham pela consolidação da criação de um novo território - a Aldeia Barragem - a qual está sendo estruturada no lugar em que se localizava o antigo canteiro de obras da Barragem Norte.

A Comunidade Cafuza, deslocada em 1992 para a localidade de Alto Rio Laeiscz, com um modo próprio de organização social, espírito de coletividade e apoio institucional, encontrou a possibilidade de construir um novo território. Mesmo enfrentando percalços advindos da minimização e/ou interrupção do apoio institucional que teve em outros momentos, reconhece ter encontrado condições de reorganização social e estabilidade depois de longo período de lutas pelo direito à terra e reconstrução de sua identidade. Este é um grupo social que persiste na luta em favor do desenvolvimento comunitário baseado nos saberes locais aliados à criação de novas estratégias de sobrevivência, mas está longe de ter ressarcidas suas perdas materiais e imateriais.

A comunidade de Barra do Rio Dollmann, simplesmente não se encontra mais naquele espaço. O lugar está lá, mas poucos moradores permaneceram. Nascentes desapareceram devido aos cortes e explosão de rochas durante as obras. Terras agricultáveis deram lugar ao maciço da barragem e aos sulcos causados pela erosão dos solos. A área em que se encontrava o canteiro de obras da barragem, pouco a pouco, deu lugar às casas e barracos levantados para abrigar famílias indígenas que se esforçam para buscar lugar de moradia mais próximo do emprego, fugindo do isolamento causado pelo alagamento das estradas de acesso às aldeias.

As considerações aqui elaboradas não conseguem identificar a totalidade das influências da implantação da Barragem Norte sobre as comunidades atingidas. O que se pode 
dizer é que, a cada momento, essas comunidades se deparam com novos cenários, novas situações, novos medos e incertezas. A edificação da obra contribuiu para o agravamento das históricas situações de conflitos interétnicos entre os grupos que formam a população do município de José Boiteux. A própria condução do processo de ocupação e desenvolvimento local favoreceu a ocorrência desses conflitos, mas a construção da Barragem Norte potencializou situações de instabilidade e conflitos entre grupos com diferentes interesses.

Para lidar com estas situações os integrantes dessas comunidades precisam perceber seus territórios como espaços constituídos pelo conjunto formado por eles, enquanto indivíduos de cultura e identidade própria, e pelos recursos que estão ao seu alcance, bem como precisam perceber que é por intermédio do uso de seus saberes, aliados à criação de alternativas apropriadas ao seu contexto, que a reprodução da vida e as possibilidades de seguir em frente se tornam possíveis.

\section{Referencias Bibliográficas}

CRÉPEAU, Robert R. A contribuição de Sílvio Coelho dos Santos ao estudo dos Jê do Sul. Ilha-Revista de Antropologia, v. 10, n. 1, Florianópolis, p. 259-272, jan./jun. 2008.

FRANK, Beate. "Uma história das enchentes e seus ensinamentos" in: FRANK, Beate; Pinheiro, Adilson (orgs.). Enchentes na Bacia do Itajaí: 20 anos de experiências. Blumenau: Edifurb, 2003.

FRAGA, Nilson César. Obras Por Mais de Uma Década - estudos do processo de construção da Barragem Norte no município de José Boiteux/SC. Relatório técnico CNPq - UDESC. Florianópolis, 1997.

FRAGA, Nilson César. As Enchentes do Vale do Itajaí-Açu, SC: das obras de contenção à indústria da enchente. Dissertação de mestrado - PPGEO/UEM. Maringá, 2000.

IBGE- Instituto Brasileiro de Geografia e Estatística. Censo 2010. Disponível em: www.censo2010.ibge.gov.br. Acesso em: 21 Maio de 2015.

MARTINS, Pedro. Anjos de Cara Suja. Etnografia da Comunidade Cafuza. Petrópolis: Vozes, 1995.

MINAYO, Maria Cecília de Souza (org.). Pesquisa Social. Teoria, método e criatividade. 18 ed. Petrópolis: Vozes, 2001.

MÜLLER, Sálvio A. Opressão e Depredação. Blumenau: EdiFurb, 1987.

PATTÉ, Ana Roberta Uglõ. Barragem Norte na Terra Indígena Laklãnõ. Trabalho de conclusão de curso - Licenciatura Intercultural Indígena do Sul da Mata Atlântica/UFSC. Florianópolis, 2015.

SANTOS, Milton. Espaço e Sociedade. Petrópolis: Vozes, 1979.

SANTOS, Milton. Da Totalidade ao Lugar. São Paulo: Edusp, 2008. 
SANTOS, Sílvio Coelho dos. Índios e Brancos no Sul do Brasil: a dramática experiência dos Xokleng. Porto Alegre: Movimento, 1987.

SANTOS, Sílvio Coelho dos. A barragem de Ibirama e os índios. Geosul, v.2, n. 4, Florianópolis, p. 42-47, jul./dez. 1987 b.

VAINER, Carlos B. "Conceito de 'Atingido': uma revisão do debate” in: ROTHMAN, F. D. (ed.). Vidas Alagadas: conflitos socioambientais, licenciamento e barragens. Viçosa: Editora UFV, 2007, p. 39 - 63.

Recebido em outubro de 2016. Aceito em janeiro de 2017. 